\title{
Kamil Lipiński
}

Adam Mickiewicz University in Poznań

\section{The Fragmentary Narrative in the Nomadic VJ Performance by Peter Greenaway}

In discussing the relations between performance art and cinema, one faces complex questions of narrative, transmedia storytelling and mutual intersections between film and media. The purpose of this article is to combine different theoretical traditions to raise some questions concerning the method, as there is no single discourse in the field. This methodological grid may contribute answering important questions related to relocation to the new territory by post-cinematic aesthetics inscribed in the field of expanded projections. Following these lines of inquiry, this article focuses on nomadic images in the context of audiovisual production in the Tulse Luper VJ Performance. This conceptual framework may help us to refine our understanding of the auteur's touch as a tool of audiovisual production spread between text and image. In other words, this essay aims at finding a descriptive language for recapturing transmedia storytelling in performative art.

Peter Weibel introduces his remarks on narrative theory by claiming that the new aesthetic mode of deconstructive practice has been developed in a manifold manner. As he argued: "video artists in the 1990s continue the deconstruction of the cinematographic code in a more controlled, less subjective way, applying strategies that are more methodical and more precisely oriented to social issues than those of the 1960s" (Weibel, 2002, p. 47). According to this passage, cinema is disappearing into a larger stream of audiovisual media.

The emergence of new media has moved cinema from a central position to an element of the wider narrative structure of the live event. An advent of digital technologies has emerged as a result of "fragmentation, spacing, exhibition, piecework and exhaustion have begun to arrive at their extreme limit" (Nancy, 2003, p. 123). Patricia Pisters has demonstrated convincingly that "in discussions on the fate of the cinema in the digital age it is commonly argued that the cinematographic image has died either because image culture has become saturated with interactive images, as Peter Greenaway argued on countless occasions or because digital has 
undermined the ontological photographic power of the image, but that film has a virtual afterlife as information or art" (Pisters, 2016, p. 145).

The centrality of cinematic expression is accounted for by the transmedia storytelling of VJ real-time streaming transplanted to the fragmentary Tulse Luper saga. Greenaway's version of digital cinema is necessary to stress that the cinematic afterlife of images relies upon capturing the ontological nature grounded in the exploration of the film intrinsic material expression of visual culture. By employing various strategies and devices, "multiple projections took on the first plan of visual culture, whose intention was to liberate itself from the conventional conception of painting, technical and material restrictions of imagined technology and repressive determinants of the social codes" (Weibel, 2002, pp. 42-43). In other words, in the contemporary visual landscape, one may indicate an increasing development begun in the early 1990s for the projection of real-time images on multiple screens involving a variety of transformations drawn on touch-screen manipulation.

Francesco Casetti has pointed out that:

starting from the second half of 1990 , the film landscape has changed to such an extent that it seemed to have evaporated, disappeared.

The film may have a composite origin (Hollywood as well as home movies, but also the re-editing of work exchanged through peer-to-peer networks); it can travel through several channels, each of which enables it to model itself in a different way (an image projected on the screen, a videotape, a digital disc, a background for multimedia shows, etc.) (Casetti, 2007, p. 36).

If we agree with this proliferation, one of significant diagnosis at the end of the cinema has been introduced by Peter Greenaway in his VJ practice. Unlike the anachronistic nature of cinema, the VJ performance entitled No TV Peter Greenaway Tulse Luper VJ Performance was held on $20^{\text {th }}$ of March, 2009, at the Festival of Visual Media InSPIRACJE in the club Old Locomotive in Szczecin, as one of the venues throughout Europe. In particular, in Poland it was organized both in Szczecin, and in Cracow.

My purpose is to explore, to varying degrees, a specificity of phenomena in the realm of dispersed diegesis in chapter through the change sequence by the Video Jockey on the six freely chosen screens. This multi-screen practice of expanded cinema enters into commercial spaces outside the cinema taking the form of a temporary event in an arena of projection space. This digital, audiovisual remix in a dark multi-screen room exceeds perception as it is no longer displayed as only one, a single film on a single screen drawing our attention to fragmentary background elements of the show.

Since compositional practices have extended performative art "the last nature of the transmedial practices ensures both individual work and the entire artistic programme of new expression" (Kluszczyński, 2011, p. 133). 
Similarly, we may indicate the combination of senses, as "artists have long invested in certain technologies and in artistic forms with the hope of inducing radical synesthesia" (Lumenfeldt, 2001, p. 120). This variable framing unveils how post-cinematic works convey other media platforms and put in motion the "body and the senses and their coordination" (Elsaesser, Hagener, 2010, p. 185).

Entangled in this cinematic event, Greenaway drifts across the painting, writing, numbers, touch interfaces and multi-screen environment to form Gesamtkunstwerk, the combination of story and music, fantastic sets and high emotions drawn on increasing mediation that aspires to be "Gesamtkunstmedium". This neo-avant-garde constellation of senses reflects the way in which the window is marked by the mise en abyme strategy that brings back the experimental films of the 1960s. An employment of multiple screens marks many temporal paths and puts into motion a narrative loop within a single "directory" of digital screens that combine mobile with "virtual" (Friedberg, 1994, p. 3).

This system momentarily derails linear progression of the narrative through enchaining multiple points of view that establishes a conceptual link and condition of knowing where "an image is transformed from an indexical sign, a trace of the past presence, into an oblique two-dimensional information table. This image today can be (re)constituted in real time, it may consist of multiple frames mixing images, text, information of all kinds" (Hagener, 2008, p. 20).

Our attention is not to the mutations of cinema itself, but to the appearance of expanded cinema oscillating at the edges of the painting, theatre, film and site-specific experiment displayed on multiple screens across the audience. That variation between the text and an image does not mean a simple game with convention, but rather a methodical form exploring the parasitic, hypertextual nature of the media defined as "physical, acoustic, informational, orderly and disorderly voice" (Serres, 1982, p. 301).

This wide reservoir of aesthetic and theoretical discourse demonstrates the way in which "recombination modules from the film in other configurations, the repurposing, and repackaging" (Hagener, 2008, p. 21). The cinematic intermingling is defined on many semiotic channels, the derivative of text $B$ (hypertext) from text A (hypotext) explicitly or not using multiple types of code. These relations of meaning in aesthetic contexts bring a closer insight into the way in which "possible relations inevitably produced by a heterogeneous network of cultural discourses" depends on "materials and technology in their discursive manifestations" (Huhtamo, 2009, p. 9).

By observing the increasing dominance of electronic and digital technologies, Greenaway organised "a set of audiovisual and multimedia objects consisting of two CD ROMS, a website for expansion, several peripherals, several books, a television site, covering six 40-minute episodes, and 42 DVDs with the contents of one suitcase" (Maheu, 2010, p. 190). The basic elements of expanded hypermedia are three films, The Tulse Luper Suitcases, Part 1: The Moab Story (2003) and The 
Tulse Luper Suitcases, Part 2: Vaux To The Sea (2004), as well as The Tulse Luper Suitcases, Part III: From Sark To Finish (2004) and one compilation film A life in Suitcases (2005). Altogether, Greenaway develops his aesthetic views by building a "catalogue" of media, enriched with the multi-textual computer game Tulse Luper Journey, available freely online, after a 24-hour television series ending with simultaneous projections of a live performance.

By shifting the emphasis on perception, kinesis and expanded consciousness, which relies upon "the eco-technical", linking and connecting up bodies, placing them at the site of interconnections, interfaces, interconnections of every technical procedure far from turning bodies into "technical objects" (as is often said today, by those who think, furthermore, that they know what a "technical object" is) sheds light on them as such, through this areal connection (Nancy, 2008 , p. 89). This multiplication of works in transmedia storytelling is crucial for Greenaway, because the spectator operates

on various media platforms, and each text is a distinctive and important part of the whole. Every medium moves in the sphere in which it is best so that history can be introduced into the film [...]. While a product is a brand access point as a whole and reading through various media upholds the depth of experience that motivates greater consumption (Jenkins, 2007, p. VII)

The Tulse Luper project spans a range of semantic references resulting from parasitism on the original text and a media diversification. This VJ's kaleidoscopic nature reframed and displayed on many screens as part of a multimedia environment and spatial arrangement results from defamiliarisation of the narrative, and multiplication of points of view. This platform may be both understood as an areal place, a place of contraction as "the rule and milieu of a proximity, at once world-wide and local, one with another, instead of transcendental/immanent. In sum, we live in the techne of the neighbour" (Nancy, 2008, p. 91).

Growing out of the tradition of extended cinema, this visual phenomenon aligns with lighting spectacles by VJ Spooky, who "presents his visual blends in the form of artwork constructed in response to the original sampling sequence" "and a reference frame in the remix culture" (Blümlinger, 2009, p. 45). The flow of images in cinema makes it possible to get rid of the Platon chains to become remixed in "open-minded" VJ culture. This visual framework "mixes and depicts the complete artistic discipline of the Internet comfortably or mingles with the new cinema being bombarded by stereoscopic lights" (Coumol, 2001, p. 29).

The VJ's mixing practice on the touch interface is considered as a "unique ephemeral action in real-time imagery taking place in a continuous relation with the sound layer and the space of presentation. The VJ operates with pre-streamed or streaming material, or material generated at the time of access, combining possible sources into unique visuals of samples" (Lewandowska, 2013, p. 102). 
Such ramblings across media are expressed in the movement of "nomadic images that intersect with each other, complement each other, and co-create leading to the constitution of the whole shape of work, simultaneously maintaining the open structure in terms of interactivity" (Kluszczyński, 2011, p. 125).

More importantly, this multiscreen, multi-track collage of video and sound deploys his interest in the first structural films concerned with frame issues and electronically-based works, such as $A T V$ Dante (1988), co-realised with Tom Phillips and individually Prospero's Books (1988) and Mas Mozart (1991), Stairs 1 Geneva (1994) ending up with a dylogy devoted to the life and work of Rembrandt Harmenszoon van Rijn. This storytelling sheds new light on the relocation to the new territories, including galleries, exhibition halls, and even commercial spaces.

These audiovisual productions reflect a temporary event arising to "new visual communication leading towards the exit of the cinema, i.e. expanded cinema that included film projections alongside the other forms of light plays - slide shows, coloured glares, strobe lights, mirror balls - multi-screen shows that became a marked visual practice of the show of the sixties" (Friedberg, 2006, p. 207). These images date back to the tradition of polivision launched for the first time in Napoleon (1927) directed by Abel Gance divided into three screens.

This VJ environment provides an insight into a "black, completely internal environment, dominated by the sequence and controlled viewpoint in the room design, where the projection space was architecturally enclosed, accompanied by the impression of 'distressing alienation "' (Clifford, 1990, p. 222). The VJ spectacle emerges as an architectural expansion relying upon the "diffusion of architecture created in wandering collected works, re-organized in a non-stop mise en cadre" (De la Rosa, 2008, p. 35). By putting an emphasis on the internal structure of the actualised work, one medium is the internal part of another and bears the marks of self-reflection and image architecture entangled in the projection. By employing the strategy frame within a frame, Greenaway makes many interesting modifications, morphing and incrustation. These visible states are oriented towards the "interior" of the screen monitor. Thus he builds an intertextual mosaic and challenges the "purity" of modern aesthetics proclaimed by Clement Greenberg and Michael Fried to demonstrate how "without the former, an uninstructed viewer perceives, would (and did) see the paintings of Jackson Pollock as 'nothing but wallpaper" (Mitchell, 2007, p. 396). This internal construction of an actualised work expresses the desire for 'nesting' one medium that appears in another medium as a content"(Mitchell, 2007, p. 401). This intersection oscillates on the edge of many disciplines such as painting, film history or theatre bridging the gap between the theory and the practice to stimulate critical exchange between them.

In particular, Greenaway, in Tulse Luper's Suitcases, introduces a "map, showing the direction of cartography where the stylisation shows an effect of entering the map. The hero walks, actually 'flows', in virtual reality resembling a computer game" (Jakubowska, 2007, p. 78). 
Greenaway's discussion on spatial wandering demonstrates how theoretical travel "presents a topological and symbolic space where the visitor could enter like in a "cultural journey" "fascinated by cartography, who collects maps, creates cartographical works, draws serial paintings and landscapes in which grids and crossing lines often occur" (De Rosa, 2008, p. 37). More specifically, this transmedia performance announces the birth of "augmented space" proclaimed by Lev Manovich as physical space filled with electronics and visual information. This audiovisual work "gives us new terms with which to think about previous spatial practices" (Manovich, 2006, p. 225).

The VJ auteur's touch unveils the situation in which "the space information is materialised in this case, becoming something of a monumental sculpture, not just an ephemeral, immaterial layer superimposed on physical space" (Lewandowska, 2013, p. 103). These VJ spectacles are marked by the development of aspirations to "get out of the theatres" launched by taking up new art territories, starting from 1994 when he "has introduced 100 small wooden stairs around Geneva where they have served as a viewing point for seeing specific city images for one hundred days in one hundred selected Geneva locations [...]. In Geneva the installation of this project constitutes a laboratory annex to the Draughtsman's Contract, which unmasked the prospective painting in all of its geometric calculations" (Gwóźdź, 2015, p. 185).

Let us note that the relocation of new territories aligns with the dislocation between signifier and signified inscribed in hypertextual storytelling to reflect the journey across discursivity, moving smoothly between disciplines, without finding a stable place in any of them. This "theatricalisation" of space entails limitations of the space and tableau in Euclidean geometry. A VJ performance may be compared to the "theatrical space opened up here is the space where culture doesn't simply exist - as Mieke Bal puts it - but happens" (Bal, 2002, p. 243). This combination of the visual and auditory sphere in imagination builds up the prolific status of the show enriched with a reservoir of sensual experience.

The audiovisual project No TVI Peter Greenaway Tulse Luper VJ Performance incorporates various textual elements appearing directly on the screen. This topos of space and time entangled in the hypertextual frame is triggered both on modern interfaces and software. The viewer perceives the spectacle in terms of a rupture with the box scene in the cinema and subsequent introduction of the VJ onto the stage. Similarly, the Lumière brothers both rejected a theatre scene immersed in VJ spectacle situated in front of this expanding screen environment and transformed into what Ortega Y Gasset defines as a hyperactive person.

The methodological awareness on imprisonment in the cinema, as Anne Friedberg pointed out, has been developed strongly in film theory, both by Charles Musser and by Jean-Louis Baudry. The latter compares the immobile position to the situation of the spectator in the interior of the Plato cave in which the people are kept in captive units seen as the shadow of the world of ideas. In a similar 
manner, the screen in the cinema immobilises its user in space just as "a medieval book chained to a table can be considered a precursor to the screen that 'fixes' its subject in space" (Manovich, 2002, p. 342).

Similarly, expanded cinema transgresses the concept of the "fourth wall" introduced by Bertolt Brecht, as an impassable barrier in the theatre, in contrast to the theatre ramp separating the stage from the audience. This ontological change of perspective transforms the perception of the world picture in the Heideggerian sense. Thus the fragmentary narrative of a kaleidoscopic experience in a VJ performance expresses modernity itself, as it becomes a machine that disintegrates fixed perspective: "shifting and labile arrangements" (Bukatman, 1998 , p. 78). One specific feature of this work is kinesis and immersion that entails "kaleidoscopic" disunity (Bukataman, 1998, p. 78). In parallel, Raymond Bellour suggested that these "projections of images may offer the concept of a renewed text otherwise unattainable. It is not so much a proper quality of the distant, since one can, on the contrary, in the installation, approach the image often with the help of the physical circulation" (Bellour, 2012, p. 129). This travel across the media defines in a broader sense the situation when "art takes on a nomadic character, abandoning the permanent positioning of a particular aesthetic homelessness. [...] finds the strength of his expression, the expressiveness of artistic gesture, energy, values and sense, and paradoxically his own place: always in between" (Kluszczyński, 2009, p. 133).

There is no specific point of view, in which the spectators may focus on moving around the room in the multi-pathed narrative environment to create their own reception of the spectacle divided into many visions and voices. In this arrangement, one may pass it and come back, wander in the audiovisual circuit between the vision and the sound like a kinetic stream of images derived from previous worlds. Unlike the "scopic regimes of modernity" forcing oneway point of view associated with the presence in a darkened room, Greenaway's audiovisual, manifold work activated by the VJ makes it possible to choose a path entangled in individual stories of particular variants in subsequent sections of events.

Greenaway expresses the desire to work on the touch interface to trigger fragmentary narrative stored in a data set. In other words, "Greenaway's project would thus be double data storage, the provocative encyclopedia of the last century and at the same time a narcissistic opus magnum of the same director, in which he used characters, images, and music from their earlier works (Szewczyk, 2015, p. 301). This multi-screen panorama exposes a single movie by minimizing it to one of the background elements in the composite layout of the whole project. Eye-catching modifications are scratched in these spaces shifting our attention from iconography to the sensual stimulation of an aesthetic landscape. According to Gertrud Koch, "empathic immersion in the sensually material side of object worlds such as rhythm, colour, morphology, and others, evokes a haptic perception of the projected world image" (2016, p. 39). 
As a symptom of the post-photographic era, the storytelling is "doubly articulated" as a part of an intertextual or even hypertextual journey across the media (Mitchell, 1992, p. 39). In particular, Tulse Luper stories demonstrates the way in which Greenaway may "imprison the world in ninety-two suitcases" (Peters, 2009, p. 321).

The development of numerology in Greenaway's earlier works began in the film The Draughtsman's Contract (1982). Let us note that the first appearance of the number 92 in the film Drowning by numbers (1982) is the logical alternative of numerical structure across Zet and two zeros (1985) and Pillow Book (1997), in which the numbers embody the development of iconic and structural images. The crux of the Tulse Luper project tackles the journey between the media and a story that spans six decades of Greenaway's Time of Uranium, from the discovery of uranium in Colorado in 1928 to the fall of the Berlin Wall in 1989. This story is structured by 92 suitcases corresponding to the atomic number of uranium. The story expressed in four films finds its articulation in the computer game The Tulse Luper Suitcases. This story spread across the platforms emerges from original films moving from online platforms to VJ performances within the framework of hypertextual connections.

In a similar manner, Greenaway, by remediating images on touch interface, interplays with spectators immersed in in-between projections. This remix makes it possible to associate the various fragments with one another and to intensify sensations associated with wandering glances based on "the widening of one screen to multiple screens, from one projection to multiple projections, it not only expands the visual horizons and overwhelms intensification of the visual experience" (Weibel, 2002, p. 42).

This real-time remix on touch interface permits Greenaway to "bind specific imagines of our memory with relays, stations or loci" (Belting. 2002, p. 39). The VJ presents different possible exits and transitions triggered and navigated on the tactile interface. This collage of images allows us to revive the spectacle by capturing the space for a transient moment. This passage of various forms of media may serve as an "exchange arena" and internal "translation" between diverse cultural texts. This deconstruction and non-synchronic dissemination of further elements of the story entails difficulties for spectators to concentrate on the object of observation. An intensification of sensible sensations allows for specifying positions within the projection area and thus determines the way of reading the storytelling. Tulse Luper shifts a greater emphasis onto ocularcentrism, relying upon the hermeneutic principle that there is no viewing activity without the previous presupposition or the consciousness. An actualised status of the screens oscillates in tension between the place of standing and the moving diegesis on the screen. The VJ, by selecting particular sequences, demonstrates the way in which "nomadic images interweave each other and complement each other, leading to the constellation of the overall shape of the work and preserves the open structure of interactivity" (Kluszczyński, 2011, p. 133). The VJ navigates on the touch interface 
to "create further paradoxes in the moving image that can only be shown in the electronic simulation and correlation of photographic and film images. By way of an example, when the image is divided into different frames, different types of movement are shown within these frames so that every single section has its own specific movement structure. Within these inner-frames, the key images of animals and human figures in motion seem to produce continuous movement" (Spiellman, 1998, p. 62). Constant movement triggered by ontological change relies upon mixing live visual collages, a combination of visual and textual content that results in resonance.

Some parallels may be drawn between Peter Greenaway's act of mixing images on the touch interface and a painter's gesture in the process of painting an image defined by Marshall McLuhan as "specific sensory proportions". The selection of the sequence of images on the touch interface provides an insight to how to change, stop or return to the previous modification of the imaging sequence by mapping impulse. Noël Caroll argued that "we have grounds to suspect that the erotetic irregularity in the movie is not a mistake, but is intentional, we treat it as heuristic invitation or prompt to search for some other than narrative significance. In short, the failure of secure erotetic closure is what in certain cases can make other- than narrative dimensions of signification possible" (Caroll, 2008, p. 144). The fragmentary storytelling displayed on the screens makes it possible to mix images on the touch interface and select a specific order as a "trace of manual production, that everything one sees in the trace of a brush or a hand touching a canvas. Seeing painting is seeing touching, seeing the hand gestures of the artist" (Mitchell, 2007, p. 397).

Both the touch on the interface and the time-based multimedia environment obliterate the difference between the text and the image. Greenaway's philosophy may be described as the proposition of sensual theory taking writing as its object, deconstruction as its activity, whose aim is to critically look at the history of cinema. Similarly, Walter Benjamin expresses an "interchangeability of the word and pictorial message" in the poetic language of painting. In such poetic storytelling, ekphrasis seeks the emulation of pictorial and sculptural arts becoming spatial.

In parallel, Raymond Bellour finds contemporary cinema in the ambiguous situation, because he argues that the newest spectacle leads to "the wildest of ekphrasis, furiously to restore by the words of the language a time form of space that its continuity makes impossible to capture since one can already contain it under the eyes of the mind"(Bellour, 2012, p. 126). An observation of many possible perspectives brings a need for a combination of sensuality considered as a stream of audiovisual sensations as opposed to a traditional spectator's view the cinematic screen.

Importantly, Walter Benjamin suggested that reproducibility takes the aura of a work of art in brackets (2008, p. 22). Nevertheless, the presence of Peter Greenaway himself during the spectacle embodies ontological creation "hic et 
nunc" entangled in an Old Gas Works surrounded with screens. Unlike a single area of observation in cinematic space, the extended sensory reception entangled in open space, enables decentration, moving from one image sequence to the next on another screen in the projection area. The navigation across the transmedia story allows images to interweave each other, complementing and co-creating, keeping the general shape of the work and preserving an open structure. This narrative, based on different intervals within a single chapter of the stories, travels in the permanent loop being displayed on six freely selected screens and modified by the Video Jockey. Constant mediation between the various elements characterises the specific nature of projection in a circularly organised space where the sensation is inscribed in the context of the narrative story. Let us assume that this dissemination of images demonstrates how "hallucinogenic reality emerging from this congregation or from this agglomerate of images evokes an idea of opening up to this surreal, arisen, and animate transfer" (Malabou, 2004, p. 55).

In a similar manner, these "new expressions" brought to life by the touch interface, animates the eyes of the audience in the circularly developed story, revealing the fragmentary beauty and rejecting subjugation of the subject to the monocular eye in the cinema. This mobile, virtual look, which relied upon the dynamics of circulation of a motion picture between projection screens "can rebind time and again after most of it has been destroyed" (Deleuze, Guattari, 2005, p. 30). Greenaway passes through the map in contracted, areal, the fractal space of the tactile interface subjectively imposing the rhythm and sequence of images. The presence of the creator makes it possible to choose from a reservoir of images, a specific scheme in real - time using the VJ's cut, which allows you to control the flow of images. The VJ revises the story on multiple images, putting into motion the elements of the same story.

In the wake of the proliferation of imaging techniques, the cinema entered into the realm of visual art inscribed in multi-screen environments as a truly unique spectacle capable of telling one story. The presented mechanism may be compared to the dynamics of image loop constructed on the basis of touch interface logic, whose selected sequence can be altered, stopped or returned within one chapter where the image sequence became multiplied

This modern investigation has been focused on "drifting the move of thought - it is cut and configured by movement: philosophy, painting, literature, cinema with their discourses and configurations" (Lorenc, 2007, p. 136). The audiovisual staging of multi-screen projections in real-time remix reflects the fragmentary logic expressed on the touch interface by Greenaway in the platform situated in the centre of the room. These multiple, decentred sensations repeat in successive iterations on subsequent screens and unveil variants of the Tulse Luper journey in different stages of the multiplicity of heterogeneous forms and maps. In the last chapters, the hero in his journey entered the integral capitalist space and has been re- and deterritorialised. 
The multi-path storyline on the touch screen reflects how "sensation (the compound of sensations) is projected onto the well-prepared technical place of the composition, in such a way that the aesthetic plane of the composition covers it up. The material itself must, therefore, include mechanisms of perspective as a result of which the projected sensation is realised not solely by covering up the picture, but according to a depth" (Deleuze, 1994, p. 193).

A brief glance at this unattainable text enables us to pose the significant question to what extent this spectacle is visibly perceptible in the kaleidoscopic stream of lights. This effect reflects Foucaultian dispersion and draws attention to capture the spectacle in its overall dimension as a symptom of late modernity. An interface allows us to display recycling sets where "the composite sensation is reterritorialised on the plane of the composition, because it erects its houses there, because it appears there within interlocked frames or joined sections that surround the components; landscapes that have become pure percepts, and characters that become pure affects" (Deleuze, 1994, p. 197).

\section{Conclusion}

The present analysis aims at providing some methodological remarks for understanding the analytical shift from film to VJ performance. The separate words of the summaries characterise audiovisual screening employed as a tool to revitalise the old urban wastes as a platform for international events. This public multi-screen VJ performance provides a new life to the cinematic experience by stimulating multiple senses activated in different ways and in various forms by the VJ, who adapts in a newly reframed way the post-industrial environment for the time of the spectacle. The merit of such a performance is that the audience gains the freedom to move around the hall of the room in order to create their own multiple viewpoint of the performance. This coexistence of the multi-screen permits us to observe the number of fragments of the trilogy being a leitmotiv of numeracy, a focalisation of one hero activated by Greenaway in a new light of digital expression and palimpsest texture. This rearticulation of cinema on stage in commercial spaces may clearly indicate that "implementation is a condition for the functioning of the work" (Goodman, 1982, p. 283). The wandering of one art to another brings the danger of aesthetic conflicts, where each of the domains is assigned to the place of performance searching for new solutions both experimentally dangerous and enriching the canon of arts.

In the analysis of No TV Tulse Luper VJ one may hear the echo of new projection territories going towards re-use of alternative and even commercial space. This aesthetic lifting may be considered as a temporary, proliferating sensation, an act of writing on the touch interface. To conclude, it would be worth asking, as Andrzej Gwóźdź observed: 
Why not make a film, only by circulating around showrooms to mark the other cinema? And what is the cinema anyway? Disbelief of the fact that film fiction flowing down on crunchy corn can still come in handy? That you have to deprive the eye of the routine and force him to wander between the images, giving the opportunity to return and loops, jumps in constantly new passages? (Gwóźdź, 2015, p. 186)

\section{Bibliography:}

Bal M. (2002), Travelling Concepts in the Humanities. A Rough Guide, Toronto: University of Toronto Press

Bellour R. (2012), Trente - cinq ans aprés: le texte a nouveau introuvable, In La quarelle des dispositifs: Cinéma-installations- expositions, Paris: POL

Benjamin W (2008). The work of art in the age of their technological reproductibility. trans. Edmund Jephcott and Harry Zohn, In The Work of Art in the Age of Its Technological Reproducibility, and Other Writings on Media, Michael W. Jennings, Brigid Doherty, Thomas Y. Levin (red.], Cambridge/London: The Belknap Press

Blümlinger Christa (2009), Kino aus zweiter Hand. Zur Ästhetik materieller Aneignung im Film und in der Medienkunst, Berlin: Vorwerk

Bukataman S. (1998), Ultimate Trip. Special Effects and Kaleidoscopic perception, "Iris" no. 25

Caroll. N. (2008), The Philosophy of Motion Pictures, Malden, Oxford, Calden: Blackwell Publishing,

Casetti. F. (2007), Theory, Post-theory, Neo-theories: Changes in Discourses, Changes in Objects, "Cinémas: Journal of Film Studies", vol. 17, no. 2-3

Clifford J. (1990), Fourth Northwest Coast Museums, In Ivan Karp. Steven D. Lavine (red.). Exhibiting Cultures. The Poetics and Politics of Museum Display, Washing ton \& London: Smithsonian Institute Press

Coumol S. (2001), VJ Culture, "Cahiers du Cinéma", no. 10

De la Rosa M. (2008), To Look, To Wander: Cinema in Installations, "Cinéma et Cie”, no. 11.

Deleuze G., F. Guattari (1994), What is Philosophy?, trans. Hugh Tomlinson and Graham Burchell, New York: Columbia University Press,

Friedberg A. (2006), Virtual Window. From Alberti to Microsoft, Cambridge: MIT PRESS

Gwóźdź A. (2015), Instalowanie filmu, „Opcje” no. 4

Elsaesser T. i Hegener M. (2010), Film Theory. An introduction through the senses. New York, London: Routledge

Hagener M. (2008), Where is cinema (today)?, Cinéma \& Cie“, no. 2

Huhtamo E. (2009), An Archeology of the Media, London: University of California Press

Jakubowska M. (2007), Peter Greenaway. Pismo o piśmie. In Alicja Helman i Andrzej Pitrus, ed., Autorzy kina europejskiego III, Kraków: Rabid,.Jenkins H., Convergence culture. Where old and new media collide, New York, London: New York University Press, 2008

Kluszczyński R. W. (2011), Nomadic Images. Transmediality and Hybridity in Contemporary Art, "Art Inquiry. Recherches sur les Arts" no. 2

Koch G. (2016), Die Wiederkehr der Illusion: der Film und die Kunst der Gegenwart, Berlin Suhrkamp Lewandowska W. (2013), W pętli obrazów i pamięci mediów. Vj'ing, mapping i Google Street View, „Czas kultury” 2/2013 
Lorenc I. (2010), Minima aesthetica. Szkice o estetyce późnej nowoczesności, Warszawa: Scholar Lunenfeld P. (2001), Snap to Grid. A User's Guide to Digital Arts, Media and Cultures, Cambridge \& London: MIT Press

Malabou C (2004), Pierre aime les horranges, In Francis Guibal, Jean Clet Martin (red.) Sens en tous sens, Autour des travaux des Jean-Luc Nancy, Paris: Galilée

Manovich L.(2002), Language of New Media, Cambridge, Massachusetts, London: MIT PRESS

Mitchell W.J.T. (1992), Reconfigured Eye. Visual Truth in the Post-Photographic Era, Cambridge \& London: MIT PRESS

Nancy J.-L. (2003), Art, fragment, In Les sens de monde, Paris: Galilée,

Nancy J.-L. (2008), Corpus, Fordham University Press: New York

Peters H. (2008), The Tulse Luper Suitcases: Peter Greenaway's Left Luggage, In Paula Willoquet Maricondi and Mary Alemany-Galway, ed., Peter Greenaway's Postmodern and Poststructuralist cinema, The Scare Crow: Press Lanham: Maryland, Toronto, Plymouth

Spiellman Y. (1998), Intermedia and Organization of the Image: Some reflections of Film, Electronic, and Digital Image, "Iris" no. 25

Szewczyk M. (2016), W strone wirtualności. Praktyki artystyczne kina wspótczesnego, Warszawa: Instytut Badań Literackich PAN

Weibel P. (2002), Narrated Theory: Multiple Projection and Multiple Narration (Past and Future), In Martin Riser, Andrea Zapp, ed., New Screen Media. Cinema/Art./Narrative, London: BFI

Publishing

\section{Fragmentary Narrative in the Nomadic VJ Performance by Peter Greenaway}

The article explores fragmentary, transmedia images of the nomadic Tulse Luper VJ Performance in terms of activation of the senses. Considering its key characteristics (such as mobility of the spectator, the multiplicity of viewpoints, fragmentary storytelling), this VJ screen-based performance challenges ordinary assumptions of the cinematic experience. This perspective sheds a new light on the areal connection of the multi-screen environment that exceeds the perception of one linear story in favour of a kaleidoscopic stream of images and ekphrastic writing. By analysing spatio-temporal specifics of the No TV Tulse Luper VJ Performance, this methodological study attempted to demonstrate that the VJ projection could not only be perceived as a reconfiguration of the basic trilogy but also as a unique, non-linear, touch-based manipulation of storytelling that aims at transforming a cinematic event into a real-time, expanded audiovisual project.

Keywords: Peter Greenaway’s VJ performance, non-linear storytelling. 